\title{
Mobile Augmented Reality (MAR) Berbasis Marker Sebagai Media Simulasi Jilbab Virtual
}

\author{
Nidia Aisyiyah ${ }^{1}$, Sri Siswanti ${ }^{2}$, Paulus Harsadi ${ }^{3}$ \\ ${ }^{1}$ Teknik Informatika/STMIK Sinar Nusantara \\ Jl. KH. Samanhudi No.84-86 Surakarta, 0271-716500, e-mail: nidia.aisyiyah@sinus.ac.id \\ ${ }^{2}$ Teknik Informatika/STMIK Sinar Nusantara \\ JI. KH. Samanhudi No.84-86 Surakarta, 0271-716500, e-mail: syswanty@sinus.ac.id \\ ${ }^{3}$ Teknik Informatika/STMIK Sinar Nusantara \\ J. KH. Samanhudi No.84-86 Surakarta, 0271-716500, e-mail: paulusharsadi@sinus.ac.id
}

\section{ARTICLE INFO}

Article history:

Received 24 November 2018

Received in revised form 15 Desember 2018

Accepted 24 Desember 2018

Available online 31 Januari 2019

\begin{abstract}
Mobile Augmented Reality (MAR) is a new technology that can combine real environment and the virtual one. MAR Technology can be used, for example, in fashion store. If the customers use fitting room to try on the product, MAR application enables customer to try on the product without visiting the store. The case in this research hijab product because hijab is one of essential outfits having many creative variations for Muslim women. Moreover, hijab needs to be suitable with clothes or suit so the customers often have difficulty when they don't bring their clothes to match up. Based on functional test, the customers are satisfied with the developed application.

Keywords: Augmented Reality, Mobile Augmented Reality, Vuforia SDK
\end{abstract}

\section{Introduction}

Era revolusi industri 4.0 seperti sekarang ini ketika terjadi perubahan besar-besaran di berbagai bidang melalui perpaduan teknologi yang menghilangkan sekat antara dunia fisik dan digital para pelaku industri berlomba-lomba memanfaatkan teknologi untuk mendapatkan efisiensi dan memperluas pemasaran produk mereka.

Augmented reality (AR) merupakan salah satu teknologi yang mulai banyak diaplikasikan dibidang industri maupun non indutri. bidang navigasi antara lain prototipe virtual informasi untuk pengunjung kampus yang dikembangkan oleh T. Hollerer [1],personal informasi untuk turis situs bersejarah Olympia [2], navigasi untuk pengunjung musium [3], dan masih banyak lagi pemanfaatan AR untuk navigasi [4][5][6][7][8][9]. bidang game seperti Pokemon GO [10], dan beberapa game AR yang lain [11][12][13]. bidang training dan pendidikan [14][15][16], bidang perakitan dan perbaikan [17][18][19], bidang kesehatan [20][21].

Teknologi Augmented reality (AR) memungkinkan pengguna melihat dunia nyata dengan objek virtual yang di tumpangkan atau dikomposisikan di dalamnya sehingga pengguna akan melihat secara nyata di dunia nyata dan tentunya teknologi ini membutuhkan sebuah alat untuk menampilkan hasil [22]. AR memiliki tiga kelebihan :

a. Mampu mengkombinasikan lingkungan nyata dan virtual

b. Interaktif secara real time 
c. Dapat dilihat secara $2 \mathrm{D}$ atau $3 \mathrm{D}$

Teknologi ini juga dimanfaatkan di bidang fashion atau tata busana salah satunya untuk mengatasi masalah fitting room. Di dunia fashion terutama pada bidang penjualan, para pelanggan harus mencoba produk secara langsung untuk menemukan produk atau barang yang cocok untuk dibeli. Hal ini membuat proses pembelian memakan waktu lebih lama. Beberapa penelitian yang dilakukan antara lain, Magic mirror yang diusulkan oleh Miri Kim yang memanfaatkan teknologi IR camera dan RGB camera untuk melakukan identifikasi pelanggan dan mengubahnya menjadi 3D avatar yang memungkinkan untuk memilih produk dan memasangkan ke avatar tersebut [23], fitting room dengan menggunakan Kinect [24], atau menggunakan image blending [25].

Tujuan dalam penelitian ini lebih spesifik di masalah fitting room yaitu untuk produk Jilbab. Jilbab adalah kerudung lebar yang dipakai perempuan muslim untuk menutupi bagian kepala, leher sampai dada. Produk ini merupakan produk dengan variasi paling banyak karena masuk dalam kategori asesoris busana. selain itu masalah lain adalah kecocokan jilbab dengan busana yang akan dipakai, padahal pelanggan tidak selalu memakai atau membawa busana yang akan dipasangkan dengan jilbab yang akan dibeli.

Teknologi Augmented Reality (AR) memungkinkan pelanggan dapat langsung memilih jilbab secara virtual tanpa harus memakainya langsung.

\section{Research Method}

\subsection{Media Augmented reality (AR)}

Media yang akan digunakan untuk aplikasi ini masuk dalam kategori Handheld display [13] yaitu mobile smartphone atau termasuk dalam kategori Mobile Augmented Reality (MAR). MAR memiliki beberapa kelebihan antara lain memiliki fitur kamera, sensor, kemampuan komputasi dan mendukung mobile cloude computing [26]. Gambar 1 menampilkan komponen dasar dalam sistem MAR.

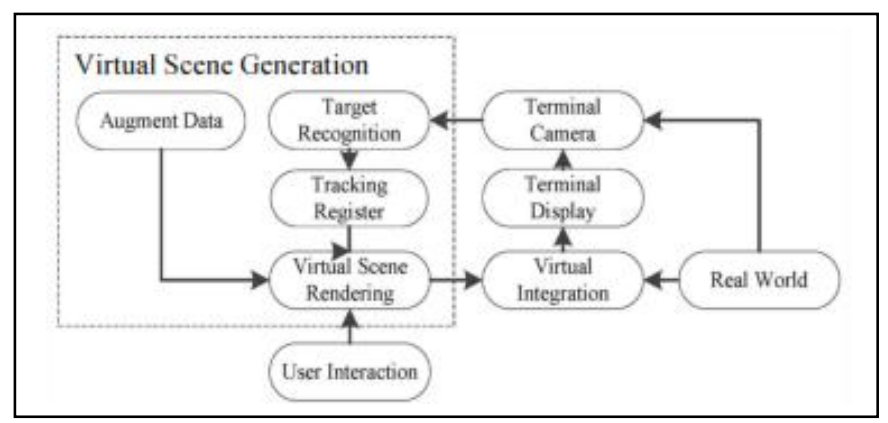

Gambar 1. Arsitektur dasar sistem MAR

\subsection{Vuforia SDK}

MAR menggunakan teknik computer vision untuk melakukan pelacakan koordinat yang tepat atas objek menggunakan teknik image processing. Ada dua teknik yaitu marker-based method dan natural feture-based method.

Aplikasi ini menggunakan marker-based method. Penanda atau marker dibuat dalam bentuk bando dan bersifat multi object. Dimana marker akan mampu menampilkan berbagai jenis objek jilbab. marker bando dapat dilihat sesuai gambar. 2 berikut.

TRANSFORMATIKA Vol. 16, No. 2, Januari 2019: 153-159 


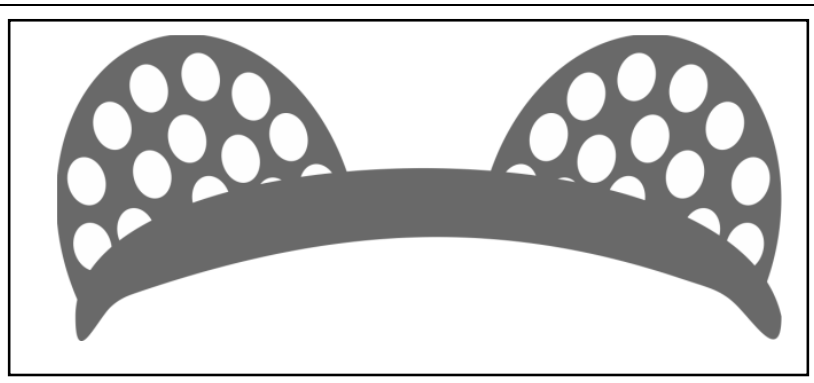

Gambar 2. Pola marker menggunakan bando

Aplikasi yang digunakan untuk membangun MAR simulasi jilbab ini yaitu Vuforia SDK yang digabungkan dengan Unity game engine baik mulai teknik tracking marker sampai penyimpanan data ke database dan menampilkan hasil Augmented reality (AR).

Vuforia SDK memiliki banyak kelebihan sebagai software development kit untuk membangun Mobile Augmented Reality (MAR). Beberapa kelebihan Vuforia SDK antara lain [27]:

- Cepat melakukan pengenalan local target

- Teknologi yang mendukung dan dapat digunakan untuk mengenali ribuan target.

- Memiliki kemampuan target traking yang mumpuni

- lebih efektif dibanding Augmented reality SDK yang lain dan mendukung pengenalan pola dengan low-light dan target yang tertutup sebagian.

Arsitektur Vuforia SDK secara umum dapat dilihat sesua gambar 3. berikut.

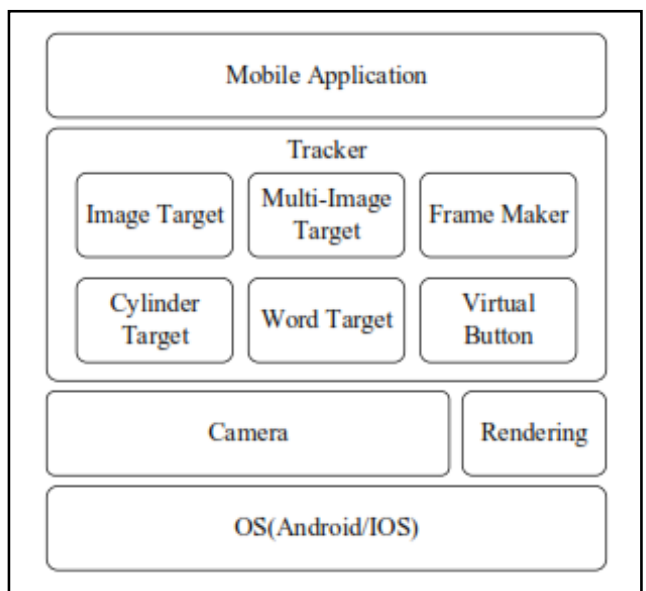

Gambar 3. Arsitektur dasar Vuforia SDK

\subsection{Arsitektur dan Flowchart Aplikasi}

Aplikasi MAR simulasi jilbab ini akan dikembangkan sesuai alur proses seperti gambar 4. dan untuk flowchart aplikasi seperti gambar 5. dengan menggunakan Unity game engine sebagai software pengembang. 


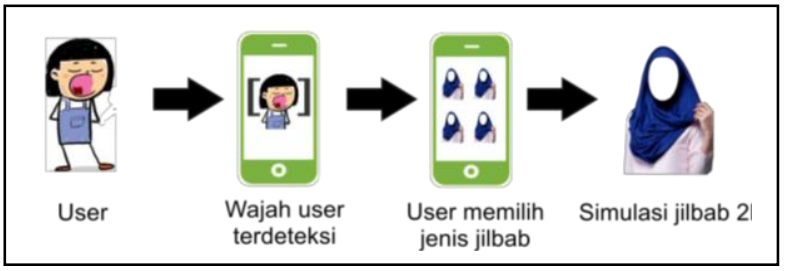

Gambar 4. Alur proses Aplikasi MAR Simulasi jilbab

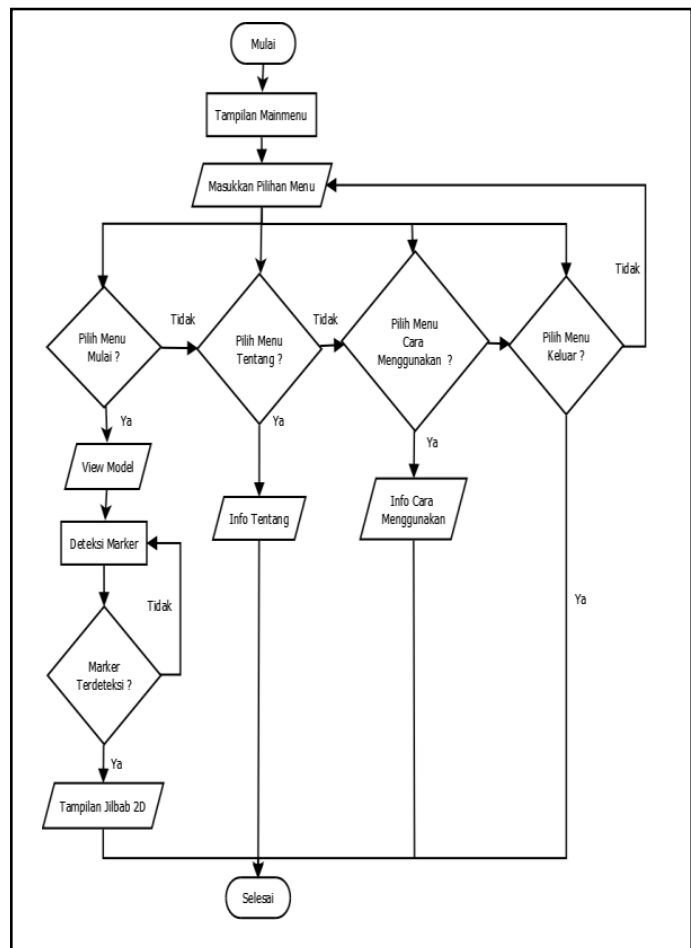

Gambar 5. Flowchart Aplikasi MAR Simulasi jilbab

\section{Results and Analysis}

Dibawah ini merupakan hasil tampilan aplikasi. Tampilan menu sesuai gambar 6 . merupakan menu utama aplikasi kemudian gambar 7. merupakan tampilan menu pilihan jilbab.

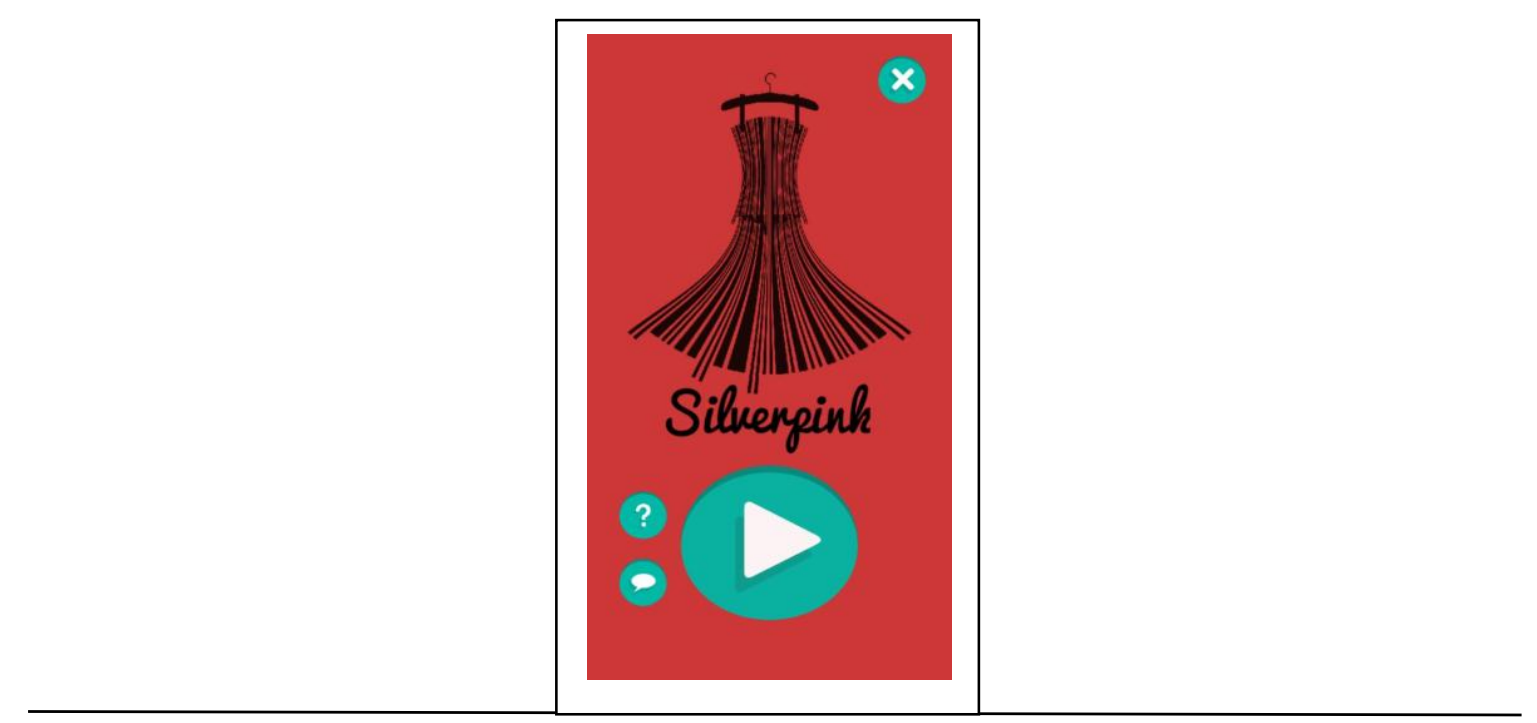

TRANSFORMATIKA Vol. 16, No. 2, Januari 2019: 153-159 


\section{Gambar 6. Menu utama aplikasi}

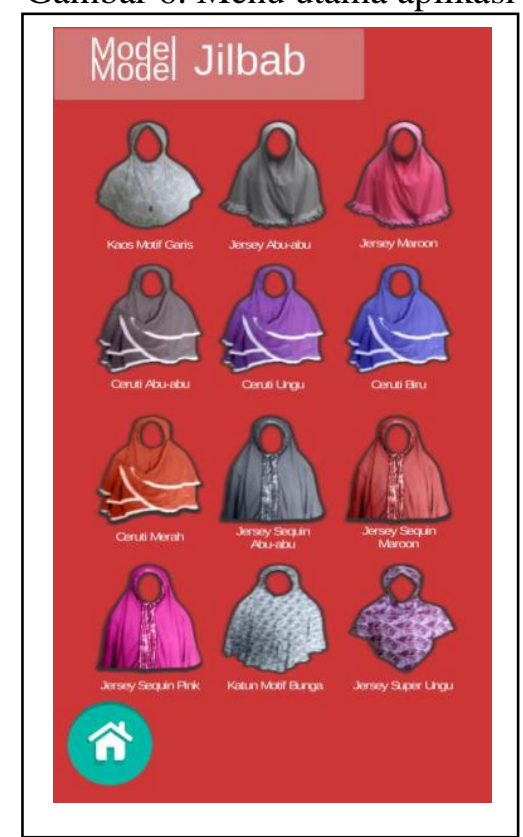

Gambar 7. Pilihan jilbab

Gambar 8. merupakan hasil aplikasi setelah pemilihan jilbab oleh pengguna.

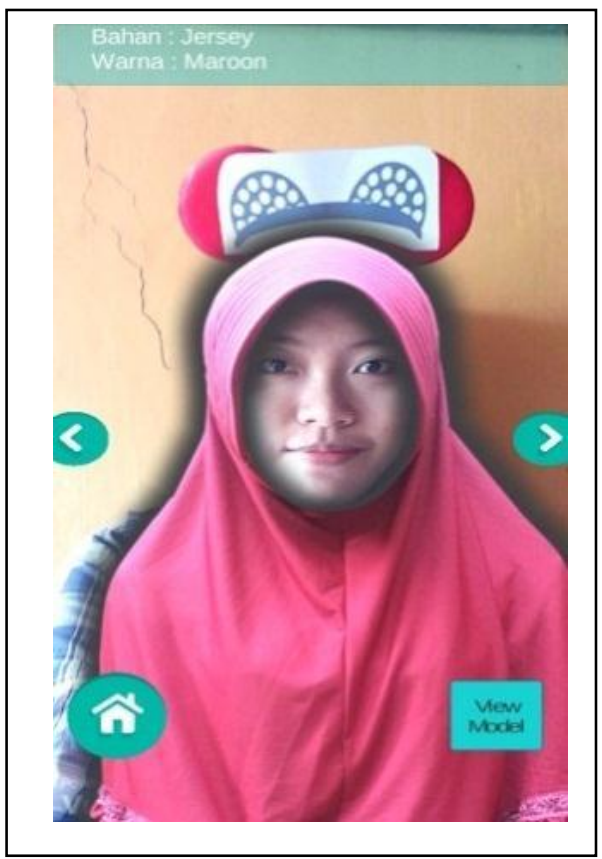

Gambar 8. Hasil aplikasi

Dibandingkan dengan hasil penelitian sebelumnya terutama di masalah fitting room seperti penggunaan 3D avatar [23], penggunaan Kinect [24], atau image blending [[25]. Hasil dari penelitian ini lebih mudah diimplementasikan dengan perangkat ringan dan mudah dibawa kemana-mana karena berbasis Mobile Augmented Reality (MAR).

Mobile Augmented Reality (MAR) Berbasi Marker Sebagai Media Simulasi Jilbab Virtual (Nidia 
Aplikasi MAR simulasi jilbab ini juga telah dicobakan untuk diuji dengan metode uji fungsionalitas sistem dengan memberikan angket kepada pengguna untuk melakukan penilaian. Angket diberikan kepada 13 orang pembeli jilbab.

Hasil angket uji kelayakan sistem

\begin{tabular}{lccc}
\hline \multirow{1}{*}{ Kriteria } & \multicolumn{2}{c}{ Jawaban } \\
\cline { 2 - 4 } & $\begin{array}{c}\text { SB } \\
(\text { Sangat } \\
\text { baik) }\end{array}$ & $\begin{array}{c}\text { B } \\
(\text { Baik })\end{array}$ & $\begin{array}{c}\text { TB } \\
\text { (Tidak } \\
\text { baik) }\end{array}$ \\
\hline $\begin{array}{l}\text { Aplikasi mudah digunakan } \\
\begin{array}{l}\text { Tampilan aplikasi MAR Jilbab } \\
\text { menarik }\end{array}\end{array}$ & $82 \%$ & $18 \%$ & $0 \%$ \\
$\begin{array}{l}\text { Tampilan objek 2D MAR dalam } \\
\text { aplikasi cukup jelas }\end{array}$ & $21 \%$ & $13 \%$ & $0 \%$ \\
$\begin{array}{l}\text { Aplikasi MAR Jilbab cukup } \\
\text { interaktif }\end{array}$ & $82 \%$ & $18 \%$ & $0 \%$ \\
$\begin{array}{l}\text { Informasi audio dalam aplikasi } \\
\text { ini cukup jelas }\end{array}$ & $80 \%$ & $10 \%$ & $10 \%$ \\
$\begin{array}{l}\text { Informasi teks dalam aplikasi ini } \\
\text { cukup jelas }\end{array}$ & $76 \%$ & $14 \%$ & $10 \%$ \\
$\begin{array}{l}\text { Marker mudah terdeteksi oleh } \\
\text { kamera }\end{array}$ & $60 \%$ & $20 \%$ & $20 \%$ \\
$\begin{array}{l}\text { Setelah menggunakan aplikasi ini } \\
\text { timbul rasa puas pada proses } \\
\text { pelayanan }\end{array}$ & $82 \%$ & $18 \%$ & $0 \%$ \\
\hline
\end{tabular}

Berdasarkan hasil pengujian diatas dapat ditarik kesimpulan bahwa secara fungsional perangkat lunak sudah sesuai dengan output yang diharapkan.

\section{Conclusion}

Aplikasi Mobile Augmented Reality (MAR) simulasi jilbab yang dikembangkan menggunakan Vuforia SDK dengan Unity game engine berdasarkan pengujian dapat disimpulkan bahwa aplikasi ini layak digunakan dan mampu mengatasi masalah fitting room produk jilbab yaitu pembeli tidak harus mencoba produk secara langsung tetapi dapat melalui aplikasi MAR simulasi jilbab ini.

\section{References}

[1] T. Höllerer, S. Feiner, D. Hallaway, B. Bell, M. Lanzagorta, D. Brown, S. Julier, Y. Baillot, and L. Rosenblum, "User interface management techniques for collaborative mobile augmented reality," Comput. Graph., vol. 25, no. 5, pp. 799-810, 2001.

[2] P. Dähne and J. Karigiannis, "Archeoguide : System Architecture of a Mobile Outdoor augmented reality system," Proc. ISMAR, pp. 263-264, 2002.

[3] P. Föckler, T. Zeidler, and O. Bimber, "PhoneGuide : Museum Guidance Supported by On- Device Object Recognition on Mobile Phones," Proc. Mob. Ubiquitous Multimed., pp. 3-10, 2005.

[4] J. Hagberg, M. Thor, and M. Wiklander, "3DVN : A Mixed Reality Platform for Mobile Navigation Assistance," Proc. CHI, no. February, pp. 1-4, 2006.

TRANSFORMATIKA Vol. 16, No. 2, Januari 2019: 153-159 
[5] D. Schmalstieg and et al, "Managing Complex Augmented Reality Models," IEEE Comput. Graph., vol. 27, no. August, pp. 48-57, 2007.

[6] Y. Tokusho and S. Feiner, "Prototyping an Outdoor Mobile Augmented Reality Street View Application," IEEE Int. Symp. Mix. Augment. Real., vol. 2, no. c, pp. 3-5, 2009.

[7] S. Vert and R. Vasiu, "Relevant Aspects for the Integration of Linked Data in Mobile Augmented Reality Applications for Tourism," Proc. Int. Conf. Inf. Softw. Technol, no. October, pp. 334-345, 2011.

[8] V. Kasapakis, D. Gavalas, and P. Galatis, "Augmented reality in cultural heritage: Field of view awareness in an archaeological site mobile guide," J. Ambient Intell. Smart Environ., vol. 8, no. 5, pp. 501-514, 2016.

[9] A. A. M. Pires, "Combining paper maps and smartphones in the exploration of cultural heritage," Ph.D. Diss. Dept. Fac. Sci. Technol., Univ. Nov. Lisboa, Lisbon, Port., 2016.

[10] D. Harborth and S. Pape, "Exploring the hype: Investigating technology acceptance factors of Pokémon Go," IEEE Int. Symp. Mix. Augment. Reality, ISMAR, pp. 155-168, 2017.

[11] W. Piekarski and B. Thomas, "ARQuake: The outdoor augmented reality gaming system," Commun. ACM, vol. 45, no. 1, pp. 36-38, 2002.

[12] A. D. Cheok, S. W. Fong, K. H. Goh, X. Yang, W. Liu, and F. Farzbiz, "Human Pacman: a sensing-based mobile entertainment system with ubiquitous computing and tangible interaction," Proc. 2nd Work. Netw. Syst. Support games NETGAMES 03, vol. 8, pp. 209-224, 2003.

[13] A. Henrysson, M. Billinghurst, and M. Ollila, "Face to face collaborative AR on mobile phones," Proc. - Fourth IEEE ACM Int. Symp. Symp. Mix. Augment. Reality, ISMAR 2005, no. May, pp. 8089, 2005.

[14] S. Julier, Y. Baillot, M. Lanzagorta, D. Brown, and L. Rosenblum, "Defense Technical Information Center Compilation Part Notice BARS : Battlefield Augmented Reality System,” Proc. NATO, pp. 9-11, 2000.

[15] E. Klopfer, J. Perry, K. Squire, M. F. Jan, and C. Steinkuehler, "Mystery at the museum: a collaborative game for museum education," Proc. th 2005 Conf. Comput. Support Collab. Learn. Learn., p. 320, 2005.

[16] A. Harahsheh, "SMART: a SysteM of Augmented Reality for Teaching 2nd Grade Students," Proc. Brit. Comput. Soc. Conf. HumanComput. Interact, pp. 27-30, 2008.

[17] G. Klinker, O. Creighton, A. H. Dutoit, R. Kobylinski, C. Vilsmeier, and B. Brügge, "Augmented maintenance of powerplants: A prototyping case study of a mobile AR system," Proc. - IEEE ACM Int. Symp. Augment. Real., pp. 124-133, 2001.

[18] M. Hakkarainen, C. Woodward, and M. Billinghurst, "Augmented assembly using a mobile phone,” Proc. - 7th IEEE Int. Symp. Mix. Augment. Real., no. May 2014, pp. 167-168, 2008.

[19] S. J. Ferguson, "Augmented Reality in the Psychomotor Phase of a Procedural Task," Proc. ISMAR, pp. 191-200, 2011.

[20] P. E. Pelargos, D. T. Nagasawa, C. Lagman, S. Tenn, J. V. Demos, S. J. Lee, T. T. Bui, N. E. Barnette, N. S. Bhatt, N. Ung, A. Bari, N. A. Martin, and I. Yang, "Utilizing virtual and augmented reality for educational and clinical enhancements in neurosurgery," J. Clin. Neurosci., vol. 35, no. October, pp. 1-4, 2017.

[21] C. Moro, Z. Štromberga, A. Raikos, and A. Stirling, "The effectiveness of virtual and augmented reality in health sciences and medical anatomy," Anat. Sci. Educ., vol. 10, no. 6, pp. 549-559, 2017.

[22] R. T. Azuma, “A Survey of Augmented Reality,” Presence, vol. 6, no. 4, pp. 355-385, 1997.

[23] M. Kim and K. Cheeyong, "Augmented reality fashion apparel simulation using a magic mirror," Int. J. Smart Home, vol. 9, no. 2, pp. 169-178, 2015.

[24] H. Park, J. Park, H. Kim, and J. Paik, "Virtual Dress-Fitting Media Art System using Kinect and Augmented Reality," TECHART J. Arts Imaging Sci., vol. 4, no. 2, pp. 10-12, 2017.

[25] B. Patel, "Design and Implementation of Virtual Fitting Room Based on Image Blending," Int. J. Adv. Eng. Res. Dev., vol. 3, no. 4, pp. 4-14, 2016.

[26] Di. Chatzopoulos, C. Bermejo, Z. Huang, and P. Hui, "Mobile Augmented Reality Survey: From Where We Are to Where We Go,” IEEE Access, vol. 5, pp. 6917-6950, 2017.

[27] C. Xiao and Z. Lifeng, "Implementation of mobile augmented reality based on Vuforia and Rawajali," Proc. IEEE Int. Conf. Softw. Eng. Serv. Sci. ICSESS, pp. 912-915, 2014.

Mobile Augmented Reality (MAR) Berbasi Marker Sebagai Media Simulasi Jilbab Virtual (Nidia 
